\title{
Sintering Behavior of Mo Powder Compact Applied SPS Spark Plasma Sintering Method
}

\author{
Takashi Sakamoto \\ Department of Mechanical Engineering, Yatsushiro National College of Technology, 2627 Hirayama-shinmachi, \\ Yatsushiro 866 .
}

Received August 9, 1996

\begin{abstract}
SYNOPSIS
In this study we used the SPS spark plasma sintering method (hereafter SPS) with single Mo powder, a mixed powder and an added $\mathrm{Ni}$ powder which was thought to promote sintering of the Mo powder. SPS is a very effective sintering method for Mo powder sintering too, because density remarkably improved when using the lower sintering temperature. But, grain particles in the microstructure grew to a large size as sintering progressed. This sintering process is significantly time dependent, while surface and boundary diffusion proceeds quickly and soon comes to an end. The density of Mo mixture added Ni powder increased more in lower sintering temperatures than the single Mo powder on SPS. However, the decrease of activation energy on densification for sintering of Mo mixture added Ni powder is smaller than that of Mo powder.
\end{abstract}

KEY WORDS

spark plasma sintering, densification, activation energy, Arrehenius' equation

\section{Introduction}

As for SPS, it is known as a synthetic processing method which can be used to sinter at a lower temperature and in a shorter time compared to the previous pressureless sintering methods (hereafter PLS $^{1,2)}$ ). These methods are applied not only for metal powder but also for ceramics powder ${ }^{3)}$ too. But they pointed out that the grain grew considerably after sintering and that it was difficult to control this trend; this study was limited to some special powders, so future research will be necessary.

Present production methods for Mo material adopts the process which directly charges electricity to compacted Mo powder to achieve temperatures and sinter ${ }^{4)}$. On the other hand, as for sintering on high melting point metals among difficult sintering powder materials, there has been no report on the utility of SPS, so in this study we carried out an experiment for Mo powder using this method and it can be expected to get a higher density.

In the experiment, we sintered single Mo powder under several sintering conditions on SPS and PLS, caluculated activation energy on densification. Furthermore, after we sintered the Mo mixture adding small amounts of $\mathrm{Ni}$ powder which was thought to promote the sintering of Mo powder ${ }^{5)}$, and investigated sintering promotion, the microstructures and the activation energies.

\section{Experimental procedures}

The powders used in the experiment were pure Mo powder (mean particle size $4.32 \mu \mathrm{m}$, Nippon Tungsten made) and carbonyl Ni powder (particle size $4 \sim 7 \mu \mathrm{m}$, Inco made, 123 type).

When SPS plasma spark sintering, we used the Sumiseki mini type spark plasma sintering machine (Sumitomo Coal Mining Co.made, SPS-510L model).

As for sintering with SPS, we used two kinds of powder: one was Mo powder and the other was mixed powder containing Mo powder and a $2 \%$ weight ratio of Ni powder. Then $5 \mathrm{~g}$ of respective powder were put into the inside diameter $15 \mathrm{~mm}$ graphite electrode material made mold, and they were single-axially pressed with the same electrode material rods from top and bottom to $29.4 \mathrm{MPa} \sim 98 \mathrm{MPa}$, and an electrical charge was applied to maintain this condition, heated up in $0.6 \mathrm{ks}$ from room temperature, and held in $5 \mathrm{~s} \sim 0.9 \mathrm{ks}$ at a sintering temperature of

1997年 9 月 
$1373 \mathrm{~K} \sim 1873 \mathrm{~K}$; then they were cooled down, coinshaped circular sintered materials were obtained. And sintering was carried out in vacuum atmosphere $\left(10^{-2} \mathrm{MPa}\right.$ or below), and temperature was measured by the radiation thermometer. The PLS of Mo powder was carried out for comparison, it was sintered in the vacuum furnace $\left(10^{-3} \mathrm{MPa}\right.$ or below) holding $3.6 \mathrm{ks}$ at each temperature after being single-axially pressed in the metal mold at $490 \mathrm{MPa}$.

The density of the obtained sintered materials measured by using the Archimedes' method. The fracture face of sintered material broaken off along thickness direction was observed by SEM.

\section{Results and discussion}

Figure 1 shows the respective relative density of each when single Mo powder was compressed to 49 $\mathrm{MPa}$. It was heated for $0.6 \mathrm{ks}$, then the SPS holding was applied for $0.3 \mathrm{ks}$ at an elevated sintering temperature; comparisons were made with PLS application at the same sintering temperature. Relative density by SPS became remarkably higher as sintering temperature increased, and it reached up to $95 \%$ at $1873 \mathrm{~K}$. But at over $1673 \mathrm{~K}$ it only marginally increased so the effect of exceeding this temperature was not much. On the other hand, density by PLS was as low as ca. $82.5 \%$ at $1873 \mathrm{~K}$. And in case of SPS, the relative density of compacted powder before sintering was measured using an other metal mold fabricated by a single-axially press with the same compacting pressure, and as we got $47.4 \%$ then we calculated based on this value. Green density in the case of PLS was $70 \%$.

The following Photograph 1 shows SEM microstructures of sintering Mo powder compacts at elevated sintering temperature after SPS. Microstructures showed that bonding with other grain particles began partially at $1373 \mathrm{~K}$ already, and at $1473 \mathrm{~K}$ we could observe the progress of the bonding more clearly. At $1573 \mathrm{~K}$ almost of all grain particles were bonded and began to grow. And we could observe closed porosities among grain particles. These trends of grain particle growth were expedited more and more as sintering temperature were raised

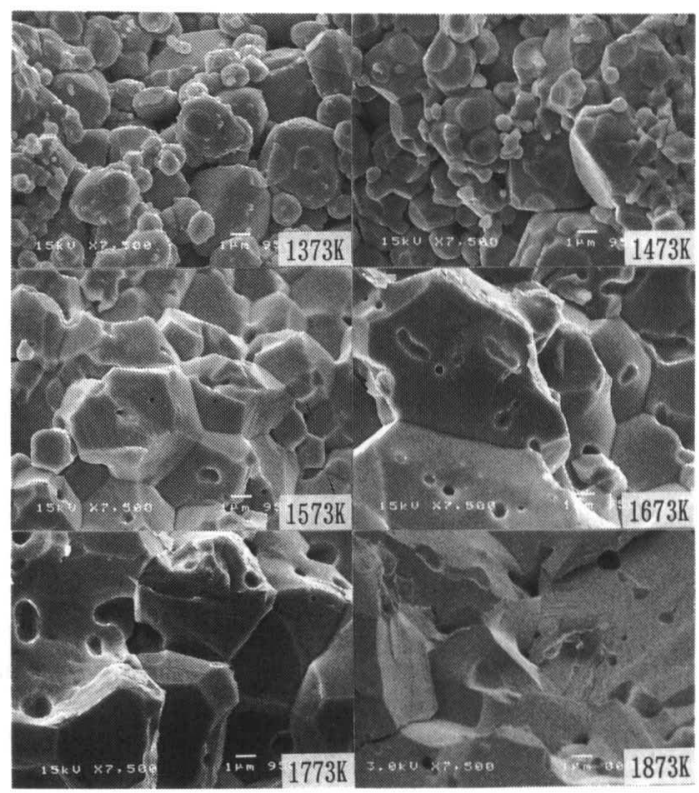

Photo.1 SEM microstructures of sintered Mo powder compacts after SPS.

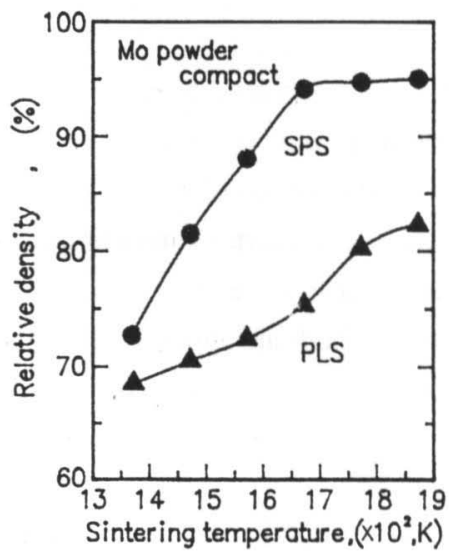

Fig.1 Relative density of Mo powder compacts after sintering at elevated temperature applied SPS and PLS.

higher, and at $1673 \mathrm{~K}$ it had already grown into huge grain particles. Density increased as sintering temperature got higher, but in the composition at 1773 $\mathrm{K}$ and $1873 \mathrm{~K}$ there existed big grown closed porosities in grown grain particles without scattering, so it was likely impossible to improve over $95 \%$.

For the next experiment, to check the influence of the compacting pressure on sintered density with SPS, keeping other conditions the same as in Figure 1, we 
sintered them changing the force from 29.4 MPa to $98 \mathrm{MPa}$, then for relative density we got the result shown in Figure 2. From this result, in case of Mo powder used on this experiment we realized that relative density was saturated at $49 \mathrm{MPa}$.

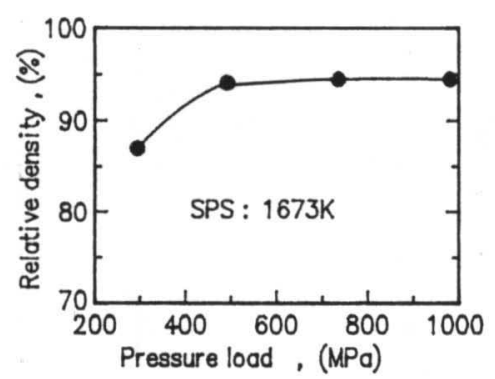

Fig.2 Relative density of Mo powder compacts after SPS at elevated compacting pressure.

When Mo powder, with Ni powder added was applied using SPS under the same conditions of single Mo powder, we got relative density as shown in Figure 3. When comparing this to the single Mo powder using SPS shown in Figure 1, it was realized that by adding Ni powder, the density was improved when using the lower sintering temperature, was very rapid at over $1273 \mathrm{~K}$ sintering temperature. At 1573 $\mathrm{K}$ it reached up to $98 \%$, so on SPS the effect of adding $\mathrm{Ni}$ powder was very drastic.

Photograph 2 shows SEM microstructures resulting from Mo powder compacts applied using SPS to the mixed powder with $\mathrm{Ni}$ powder added. In this case,

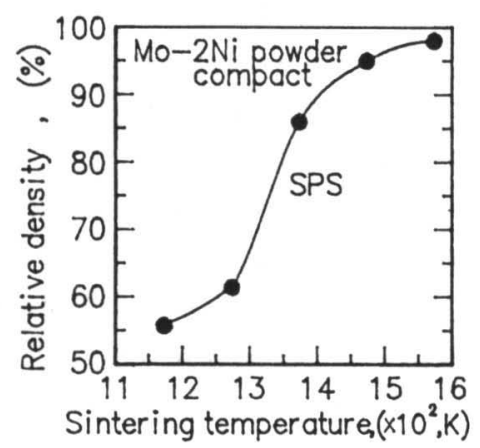

Fig.3 Relative density of Mo- 2 wt.\% Ni powder compacts after sintering at elevated temperature applied SPS. grain particle bonding started from sintering temperature was $1173 \mathrm{~K}$, and sintering progressed from lower temperatures compared to Photograph 1. In a similar fashion to the single Mo powder, the growth of grain particles was larger as sintering temperature rose, and at $1573 \mathrm{~K}$ it grew nearly as big as the grain size with the $1573 \mathrm{~K} \sim 1773 \mathrm{~K}$ microstructure of single Mo powder. But, here, very few closed pores inside of grain particles were observed in $1473 \mathrm{~K}$ and $1573 \mathrm{~K}$ microstructures; this was also a special pattern when Ni powder was added. For this reason we considered that now relative density could reach up to $98 \%$ at $1573 \mathrm{~K}$ compared with single Mo powder case.

We found that relative density using SPS was effected by a single factor i.e., the sintering temperature for either with single Mo powder and case of single Mo powder and $\mathrm{Ni}$ addition; because we thought just after the time that it reached the sintering temperature, sintering had already progressed and relative density had also improved, so we measured density when it was held for a very specific sintering temperature; then we looked for activation energy on densification by different sintering times.

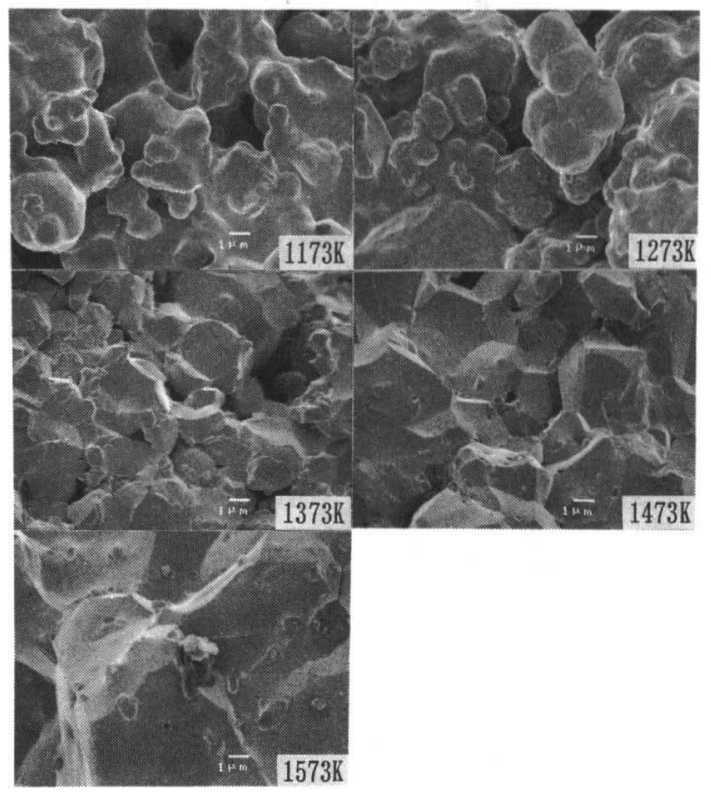

Photo. 2 SEM microstructures of sintered Mo-2 wt.\% Ni powder compacts after SPS. 
At the same time we considered the effects which short sintering time had on grain particles growth, by observation of SEM microstructures. In the case of single Mo powder, results applied on SPS setting at $1773 \mathrm{~K}$ that showed big density improvement, and below this $1673 \mathrm{~K}$ and $1573 \mathrm{~K}$ were shown in Figure 4 ; in the case of the mixed powders with Ni powder, because density was improved at a lower temperature than the single Mo powder, we could get lowered the results shown in Figure 5; sintering by $200 \mathrm{~K}$ lower sintering temperatures respectively. And as we guessed that density might change considerably in a short time, we set the sintering time for both cases at $5 \mathrm{~s}, 20 \mathrm{~s}, 60 \mathrm{~s}$ and $0.3 \mathrm{ks}$. As the obtained relative density change was so great in the figure, it shows mainly only part of the short sintering time. There is a similar trend in both Figures, i.e. relative density improved rapidly at $5 \mathrm{~s}$, then gradient became gentle but improved keeping up to $0.3 \mathrm{ks}$. As for values of relative density, comparing Figure 4 and Figure 5, Ni powder added case generally had higher values even at low sintering temperatures. Anyway, we understood that relative density improved rapidly

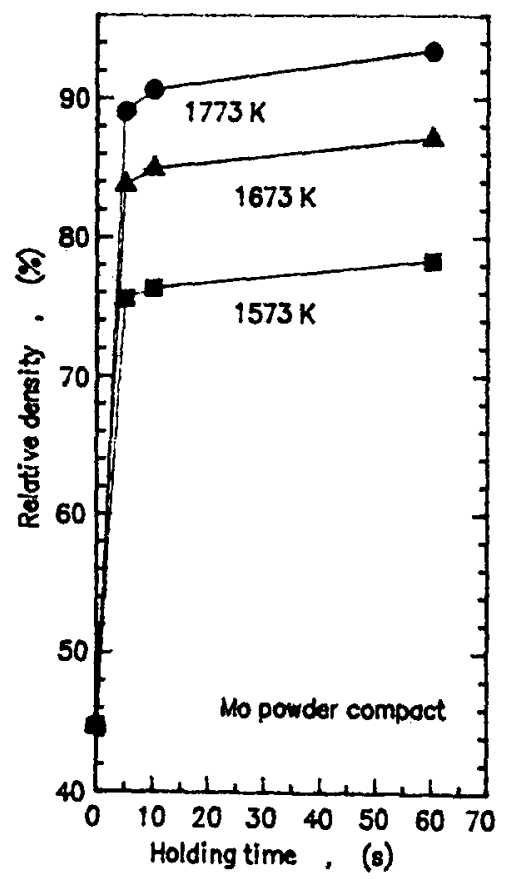

Fig.4 Relative density of Mo powder compacts after SPS for prolonged sintering time.

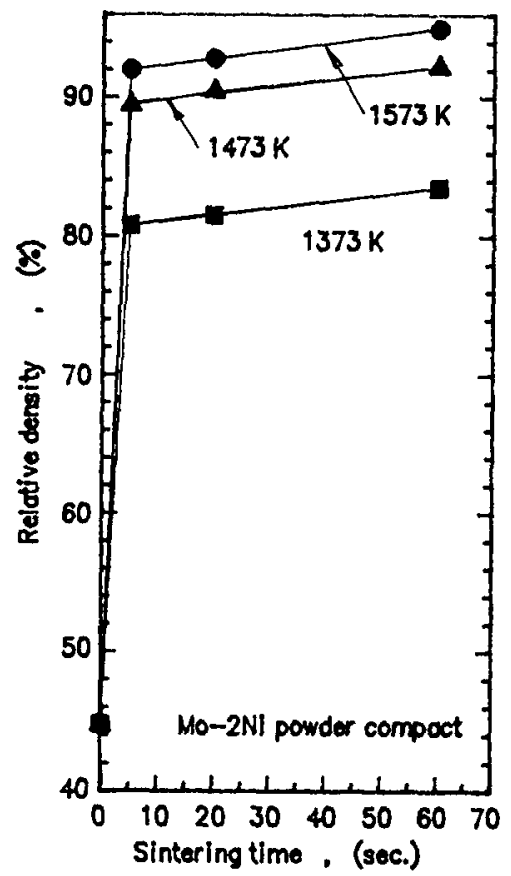

Fig.5 Relative density of Mo-2 wt.\% Ni powder compacts after SPS for prolonged sintering time.

even during very short sintering time at each temperature.

Next, from these Figures at first we took the reciprocal number of absolute temperatures on sintering to the horizontal axis, and sought improvement in the relative density obtained at respective absolute temperature as velocity for the sintering time; then we showed the plotting of natural logarithm on the vertical axis. Figure 6 shows the case of single Mo powder and Figure 7 shows the case of mixed powder with $\mathrm{Ni}$.

On these results, we calculated activation energy $\mathrm{Q}(\mathrm{kJ} / \mathrm{mol})$ for the densification by sintering, using Arrhenius' equation. That is;

$$
\ln (\mathrm{d} \rho / \mathrm{dt})=\mathrm{A} \exp (-\mathrm{Q} / \mathrm{RT})
$$

here, $\rho \quad$ : relative density $(\%)$

$\mathrm{d} \rho / \mathrm{dt}:$ density increasing rate $(\% / \mathrm{t})$ at sintering time, $t$ (sec.), on sintering temperature, $T(K)$

$$
\begin{array}{ll}
\text { A } & \text { : constant } \\
\text { B } & \text { : gas constant }(\mathrm{kJ} / \mathrm{K} \cdot \mathrm{mol})
\end{array}
$$

From the Figure, as value of gradient becomes same of $-Q / R$, then we could get $Q$. 


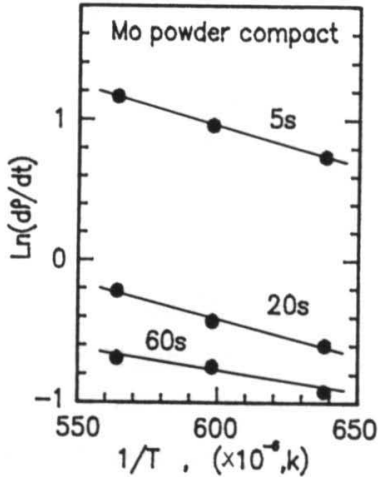

Fig.6 The relationship between $\ln (\mathrm{d} \rho / \mathrm{dt})$ and the reciprocal absolute temperature on densification for sintered Mo powder compacts after SPS for $5 \mathrm{~s}, 20 \mathrm{~s}$ and $60 \mathrm{~s}$.

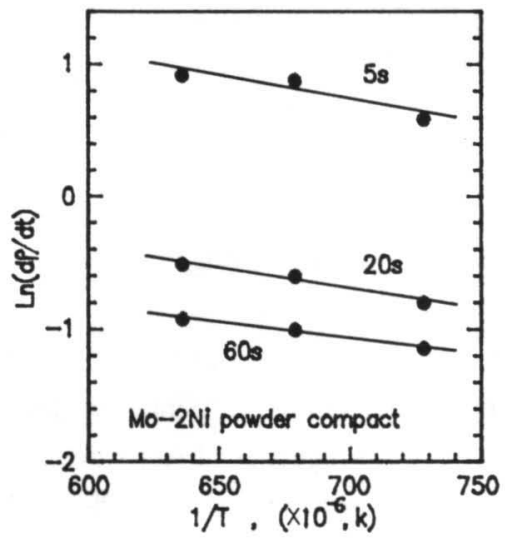

Fig.7 The relationship between $\ln (\mathrm{d} \rho / \mathrm{dt})$ and reciprocal absolute temperature on densification for sintered Mo- $2 \mathrm{wt} . \%$ $\mathrm{Ni}$ powder compacts after SPS for $5 \mathrm{~s}, 20 \mathrm{~s}$ and $60 \mathrm{~s}$.

In case of single Mo powder, calculated results from the gradient on the Figures were $47 \mathrm{~kJ} / \mathrm{mol}, 43$ $\mathrm{kJ} / \mathrm{mol}, 26 \mathrm{~kJ} / \mathrm{mol}$ and in case of Ni powder added, were $30 \mathrm{~kJ} / \mathrm{mol}, 26 \mathrm{~kJ} / \mathrm{mol}, 22 \mathrm{~kJ} / \mathrm{mol}$ corresponding holding time in the order of $5 \mathrm{~s}, 20 \mathrm{~s}$ and $60 \mathrm{~s}$ respectively. These activation energy $\left(263 \mathrm{~kJ} / \mathrm{mol}^{6}\right)$ in surface diffusion of pure Mo powder at sintering. Namely, the sintering progress is apparently time dependent, the densification progresses rapidly at the initial stage of sintering for a very short time. As activation energy, $47 \mathrm{~kJ} / \mathrm{mol}$, at $5 \mathrm{~s}$ in holding time with SPS applied is much smaller than that of the surface diffusion of the Mo powder at sintering, and SPS is very effective on densification of Mo powder sintering. On the other hand, activation energy in the case of mixed powder with $\mathrm{Ni}$ decreases from $47 \mathrm{~kJ} /$ mol to $30 \mathrm{~kJ} / \mathrm{mol}$, the decreasing value is insignificant. Accordingly, SPS is more effective than improvement due to $\mathrm{Ni}$ powder addition on densification at sintering. Photograph 3 shows SEM observation of microstructures when single Mo powder was sintered at $1773 \mathrm{~K}$ and kept sintering for a short time. Sintering in $5 \mathrm{~s}$, bonding between grain particles had already progressed and at $60 \mathrm{~s}$ it grew to be very significant. Compared to Figure 2, bonding and the size of grown grain particles showed that microstructure in sintering $5 \mathrm{~s}$ were almost as similar as the microstructure sintered at $1573 \mathrm{~K}$; furthermore relative density of both at this time indicated the same level of $88 \%$ $89 \%$. Therefore even using SPS, grain particles grew as sintering progressed and their size nearly correlated with relative density.

\section{Conclusions}

We applied SPS to single Mo powder and mixed powder with $\mathrm{Ni}$ and reached the following conclusions.

1) SPS is a very effective sintering method for Mo powder sintering, because density remarkably improved at lower sintering temperatures.

2) Relative density reached to $94.1 \%$ at $1773 \mathrm{~K}$ sintering, nevertheless improvement by further raising temperature was insignificant.

3) Grain particles in the microstructure grew to large

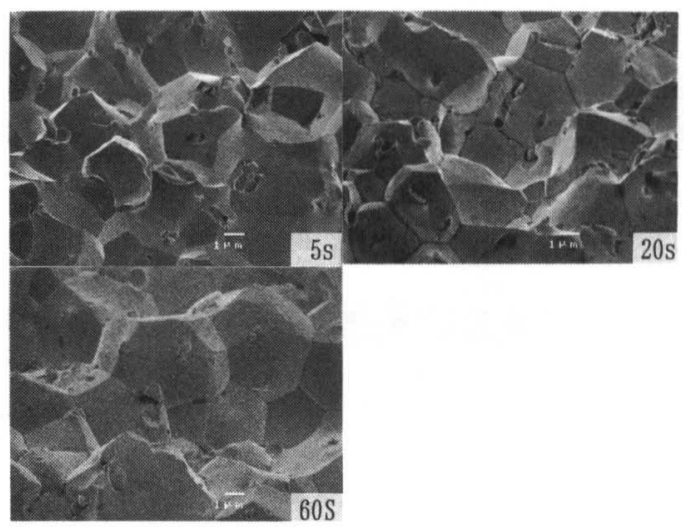

Photo.3 SEM microstructures of sintered Mo powder compacts after SPS for prolonged sintering time. 
sizes as sintering progressed, however, porosities were left to closerl pores and they were not scattered, regardless of the extent of temperature increase.

4) Relative density rose as compacting pressure increased, but it was limited in constant pressure.

5) The density of Mo mixture mixed with Ni powder increased at lower sintering temperatures more pure single Mo powder on SPS and reached to $98 \%$ at $1573 \mathrm{~K}$. This might be one reason why number of existing closed pores in the grown grain particle were fewer than in the case of the pure Mo powder.

6) The sintering promotion applied SPS is significantly time dependent. The densification process rapidly goes forwardly at the initial stage of sintering for a very short time. SPS is more effective than improvement due to $\mathrm{Ni}$ powder addition on densification at sintering, in comparison with two activation energies between pure Mo powder and mixed powder with $\mathrm{Ni}$, on densification for sintering applied SPS.

7) The size of grown grain particles in the microstructure sintered for this short time correlated well with obtained relative density values.

\section{Acknowledgments}

The author gratefully acknowledge to technology and marketing manager Masao Tokita, area sales manager Akiko Ishida and application manager masayuki Sonoda belonged to Sumitomo Coal Mining Co.,LTD. Technical Development Division which supported this research.

\section{References}

1) M.Tokita: "Trend in Advanced SPS Spark Plasma Sintering System and Technology", Journal of the Society of Powder Technology, 30(1993)790.

2) S.Matsui: "SPS Spark Plasma Sintering System and its Application", New Ceramics, 11(1993)67.

3) I.Kondo, T.Tanaka and N.Tamari: "Usefullness of Spark Plasma Sintering on Densification and Mechanical Properties of Alumina Whisker/ Zirconia Composities", Journal of the Ceramic Society of Japan, 102(1994)505.

4) M.Tsujokawa: The technical Data of Tungsten and Molybdenum, The Tungsten-Molybdenum Institute, (1988)21.

5) H.Hofmann, M.Grosskopf, M.HofmannAmtenbrink and G.Petzow: "Sintering Behaviour and Mechanical Properties of Activated Sintered Molybdenum" Powder Metallurgy, 29(1986)201.

6) R.M.German: Powder Metallurgy Science, Metal Powder Industries Federation, (1994)452. 